\title{
Potencial Prospectivo do GPR na Identificação de Depósitos Diamantíferos Aluvionares na Região de Guiratinga, Mato Grosso - Brasil
}

\author{
Prospecting Potential of GPR in the Identification of Alluvial Diamond Deposits in the Guiratinga Region, \\ Mato Grosso - Brazil
}

\section{Marcos Vinicius Paes de Barros ${ }^{1}$ (1), Welitom Rodrigues Borges ${ }^{2}$ (1), Eduardo Xavier Seimetz ${ }^{2}$ (1) \& Ricardo Kalikowski Weska ${ }^{3}$}

\author{
${ }^{1}$ Companhia Matogrossense de Mineração, Cuiabá, MT, Brasil \\ ${ }^{2}$ Universidade de Brasilia, Instituto de Geociências, Brasilia, DF, Brasil \\ ${ }^{3}$ Universidade Federal de Mato Grosso, Faculdade de Geociências, Cuiabá, MT, Brasil \\ E-mails: marcosbarros@metamat.mt.gov.br; welitom@unb.br; edu.seimetz@gmail.com; rweska@ufmt.br
}

\begin{abstract}
Resumo
A utilização de tecnologias de investigações geológicas indiretas, que fornece informações detalhadas sobre a distribuição de depósitos aluvionares, auxilia na locação de furos e escavações, otimiza os recursos e reduz os danos ambientais, possibilita um planejamento preciso e um gerenciamento eficiente dos processos de pesquisa do depósito mineral. Dentre os métodos de investigação indireta, o Radar de Penetração de Solo (Ground Penetrating Radar - GPR) mostra-se eficiente na caracterização de depósitos sedimentares aluvionares. A região da pesquisa engloba os sedimentos aluvionares do rio Garças (MT), depositados sobre rochas sedimentares da Formação Aquidauana, da Bacia do Paraná, constituindo os paleocanais e canais atuais da bacia, explorados intensamente para a mineração do diamante desde a primeira metade do século XX. Na pesquisa realizaram-se aquisições de GPR com antenas blindadas de $200 \mathrm{MHz}$ nas proximidades de antigas cavas garimpeiras de diamantes associados a cascalhos aluvionares presentes na Bacia do Rio Garças. Nas seções de GPR verificaram-se padrões de reflexão relacionados a solos, cascalhos e rochas da Formação Aquidauana. Os resultados confirmam que o GPR tem eficiência no mapeamento dos depósitos de cascalhos e do paleorelevo do embasamento rochoso, o que torna o GPR um método eficaz de prospecção para a região da Bacia do Rio Garças.
\end{abstract}

Palavras-chave: GPR; Cascalho diamantífero; Rio Garças

\begin{abstract}
The use of indirect research technologies, which provide detailed information on alluvial deposit distribution, assists the location of holes and excavations, optimizes resources and reduces environmental damage, enabling accurate planning and efficient management of mineral deposit research processes. Among indirect investigations methods, Ground Penetrating Radar (GPR) is efficient to characterize alluvial sedimentary structures. The research area encompasses Garças River alluvial sediments (Mato Grosso State), deposited on Aquidauana Formation sedimentary rocks, constituting Paraná Basin paleochannels and current channels, intensely exploited for diamond mining since the first half of the $20^{\text {th }}$ century. In the research, GPR acquisitions were carried out with shielded antennas of $200 \mathrm{MHz}$ in the vicinity of old diamond mining pits associated with alluvial gravels present in the Garças River Basin. In the GPR sections were verified patterns of reflection related to soils, gravels and rocks of the Aquidauana Formation. The results confirm that the GPR is efficient in mapping the gravel deposits and the rocky basement paleorelief, which makes the GPR an effective prospecting method for the region of the Rio Garças Basin.
\end{abstract}

Keywords: GPR; Diamond gravel; Garças River 


\section{Introdução}

Os depósitos aluvionares do tipo placeres representam importante fonte de bens minerais, como diamante, ouro e cassiterita (Marshall \& Baxter-Brown 1995; Konstantinovskii 2003). Esses depósitos se originam através do transporte de detritos rochosos em meios aquosos, onde a capacidade de transporte é controlada pela capacidade de carga do rio e a densidade da substância de interesse é determinante na concentração dos bens minerais (Carling \& Breakspears 2006; Els \& Ericksson 2006; Patyk-Kara 2008; Stanaway 2012).

A pesquisa de prospectos nas margens de rios demanda tempo em função da necessidade de licenças ambientais para a realização de sondagem, poços e trincheiras que necessitam de remoção da cobertura vegetal e, por vezes, no caso do diamante amostragem de grandes volumes de material para a obtenção de concentrações representativas do montante de minério (Kuzvart \& Bohmer 1986). Em função da distribuição errática do diamante nos depósitos aluvionares, as amostragens inferiores a $4 \mathrm{~m}^{2}$ não são utilizadas, assim como não são aceitas para a avaliação econômica do depósito (Cavalcanti Neto \& Rocha 2010).

Em função das características granulométricas dos depósitos de cascalho (seixos envolvidos por uma matriz arenosa), usam-se metodologias de pesquisa mineral que mostram elevada efetividade no delineamento de camadas e estruturas sedimentares aluvionares, como é o caso do Radar de Penetração de Solo (Jol et al. 1998; Bristow \& Jol 2003). O método Ground Penetrating Radar (GPR) consiste na transmissão e na propagação de ondas eletromagnéticas (faixa de frequência de $10 \mathrm{MHz}$ a 3000 $\mathrm{MHz}$ ), radiadas repetidamente no subsolo por meio de uma antena transmissora na superfície do solo. As mudanças nas propriedades elétricas do meio fazem com que parte do sinal seja refletido. O pulso/sinal refletido é registrado por uma antena receptora, amplificado, digitalizado e gravado (Daniels 1996; Porsani 1999). Após o processamento dos dados, o resultado obtido é uma imagem de alta resolução da subsuperfície (radargrama).

O uso do método GPR na localização de placeres diamantíferos é comum na pesquisa mineral desenvolvida por empresas (Ekes et al. 2002; Francke 2012; Fedorova et al. 2014). O sucesso das investigações de GPR depende principalmente dos contrastes entre as propriedades elétricas dos sedimentos e as rochas, da instrumentação e de parâmetros usados na etapa de aquisição de dados, das rotinas de processamento, e da experiência do intérprete (Davis et al. 1984; Neal 2004).

O objetivo do trabalho é verificar a eficiência do uso do método GPR na identificação de lentes de cascalhos diamantíferos em garimpos desativados, denominados de Sinvaldo, Xibiu e Bertinho, na bacia do Rio Garças, município de Guiratinga, MT (Figura 1).

$\mathrm{O}$ registro de ocorrência de diamantes na bacia do Rio Garças aconteceu em 1903 quando descobriram o primeiro diamante no rio Cassununga, na confluência com o rio Garças. Em 1924, todos os afluentes do rio Garças tinham garimpeiros provenientes das principais áreas de extração de diamante no Brasil (rio São Francisco, Chapada Diamantina, Minas Gerais, Maranhão e Goiás), o que ocasionou o surgimento de 44 vilas (currutelas) na região, com uma população aproximada de dezoito mil pessoas. O maior povoamento era em Cassununga, com dois mil habitantes, e a cidade de Guiratinga tornou-se a capital dos garimpos de diamante do leste de Mato Grosso (Baxter 1988).

Os depósitos diamantíferos aluviais da bacia do rio Garças ocorrem associados a paleocanais constituídos por sedimentos grossos na fração cascalho, sobre um bedrock de arenitos arcoseanos da Formação Aquidauana.

\section{Contexto Geológico}

A região do estudo encontra-se na borda noroeste da Bacia do Paraná (Milani et al. 2007). Na bacia hidrográfica do rio Garças (Figura 2A) afloram rochas da Bacia do Paraná, os grupos: Paraná (formações Furnas e Ponta Grossa), Itararé (Formação Aquidauana), Guatá (Formação Palermo), Passa Dois (Formação Irati), São Bento (formações Botucatu e Serra Geral), e Bauru indiviso. Recobrindo as rochas anteriores registram-se na área a Formação Cachoeirinha e os depósitos aluvionares (Figura 2B).

$\mathrm{Na}$ área pesquisada, o substrato geológico (bedrock) dos depósitos aluvionares é constituído por arenitos arcoseanos grossos a finos, siltitos e ritmitos da Formação Aquidauana, de idade Permo-Carbonífera (Assine et al. 1998). As estruturas primárias presentes nos arenitos são estratificações cruzadas planares, tangenciais e acanaladas, de médio a grande porte. No relevo, esta unidade litoestratigráfica destaca-se em morros reliquiares (Figura 3).

Os cascalhos ocorrem nos canais das drenagens, em colúvios e terraços laterais (Figura 4A, 4B e 4C). Estes depósitos são compostos da base para o topo, de cascalhos grossos, granulometria de seixos a blocos, com clastos de quartzo, arenitos e argilitos silicificados, calcários e silexitos. Os clastos possuem esfericidade média a alta, e mostramse subarredondados a arredondados. A matriz é composta por argila e areia grossa, por vezes apresentando cimento de óxidos de ferro, mocororô na linguagem garimpeira (Figura 4D) e em seguida por lentes de areias maturas e imaturas, por vezes lentes argilosas nos atuais terraços. 
Por vezes notam-se orientações de seixos nos cascalhos coluviais que indicam a direção do movimento de massa. Nos garimpos foram observadas armadilhas estruturais (traps), do tipo canoão e ajogo, no embasamento rochoso que condicionam a geometria dos depósitos de cascalhos. O canoão é um canal de corte e preenchimento (cut and fill) e o ajogo corresponde aos cascalhos depositados nos meandros (Figura 4E) das drenagens (Weska 1996a).

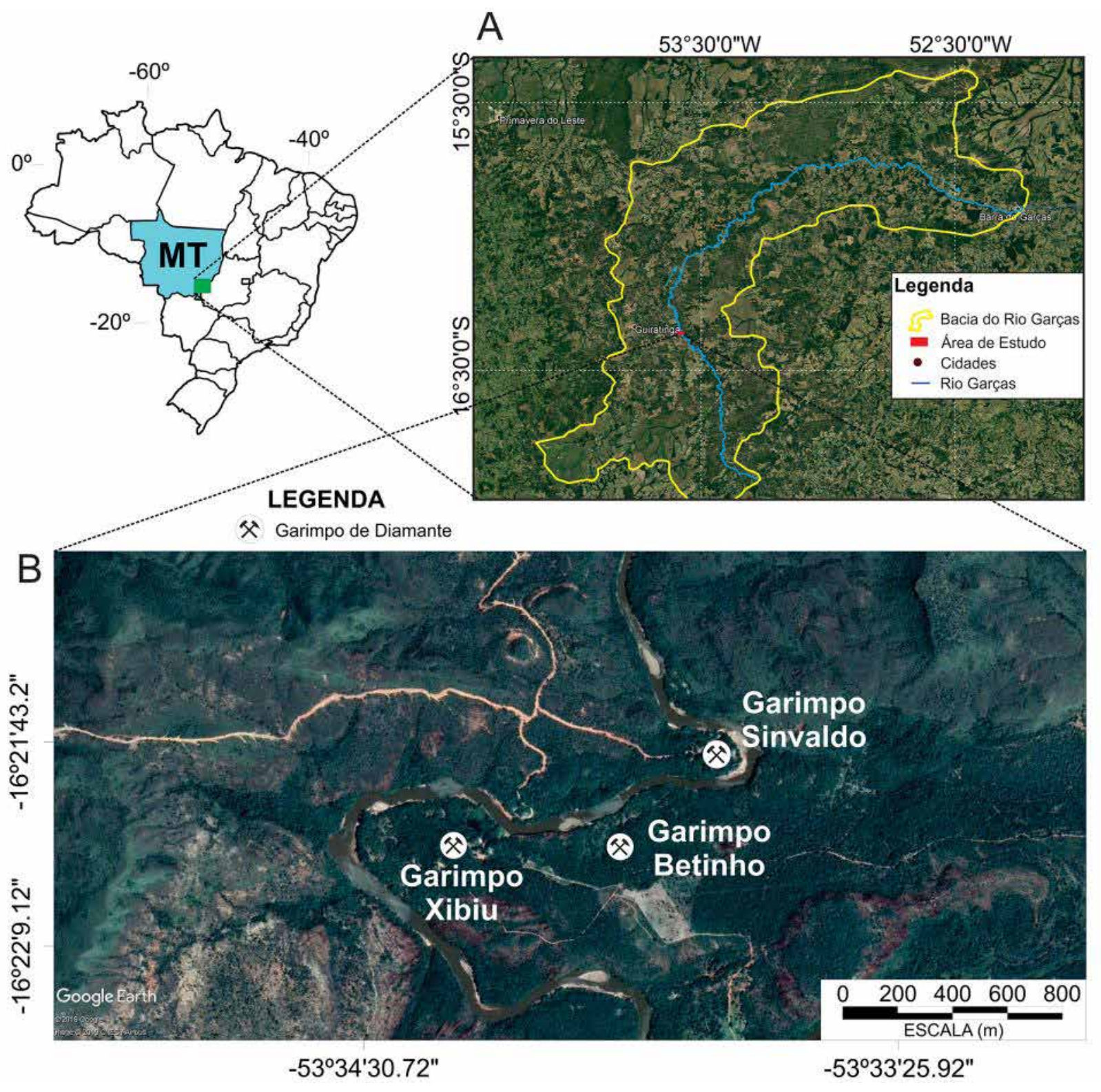

Figura 1 Mapa de Localização da área de estudo com a indicação dos garimpos do Xibiu, Bertinho e Sinvaldo, município de Guiratinga, MT (Fonte: Google Earth). 


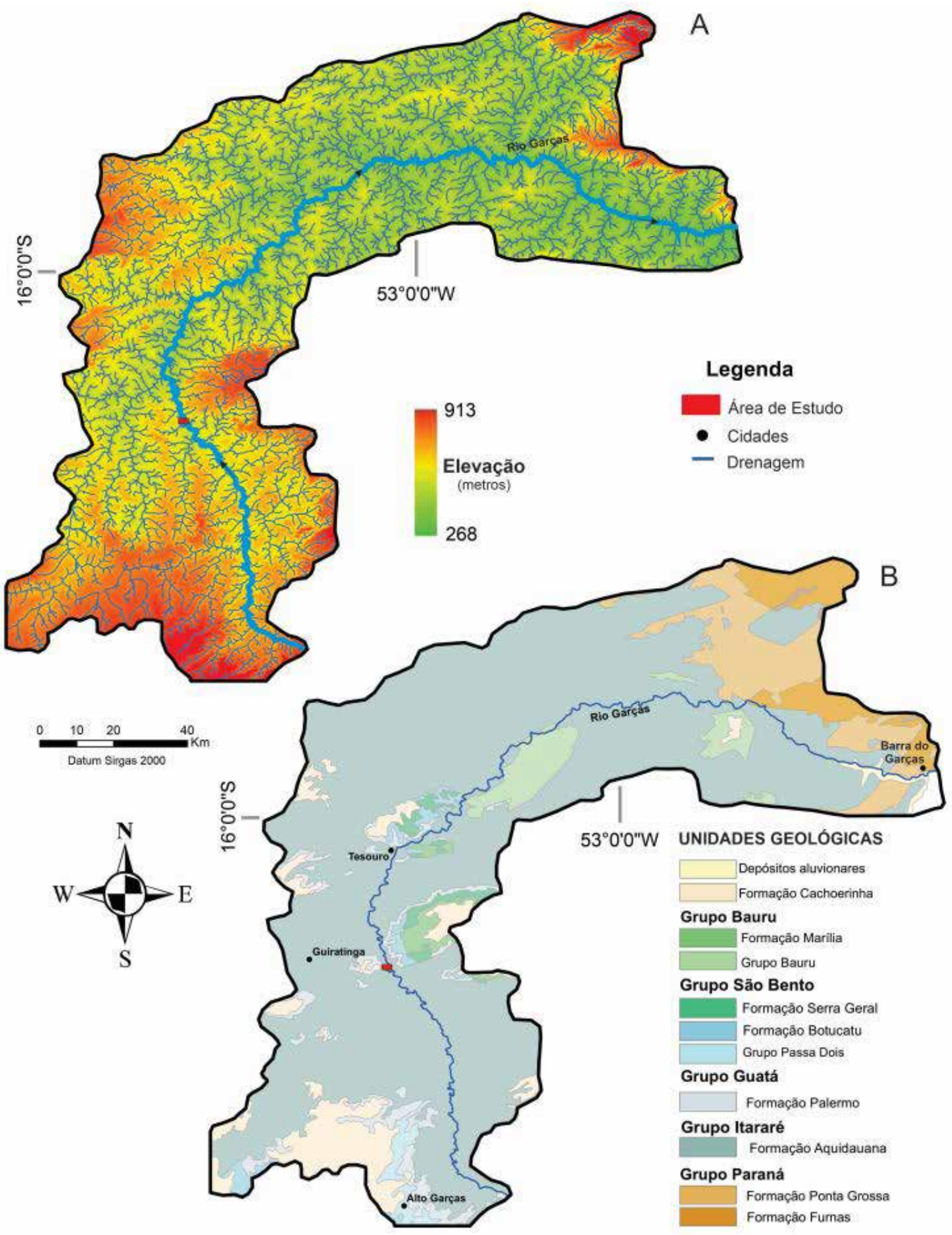

Figura 2 A. Mapa da Bacia hidrográfica do rio Garças com a rede de drenagem; B. Mapa geológico da bacia do rio Garças com as principais unidades geológicas mapeadas e a localização da área de estudo (Extraído de Lacerda Filho et al. 2004). 

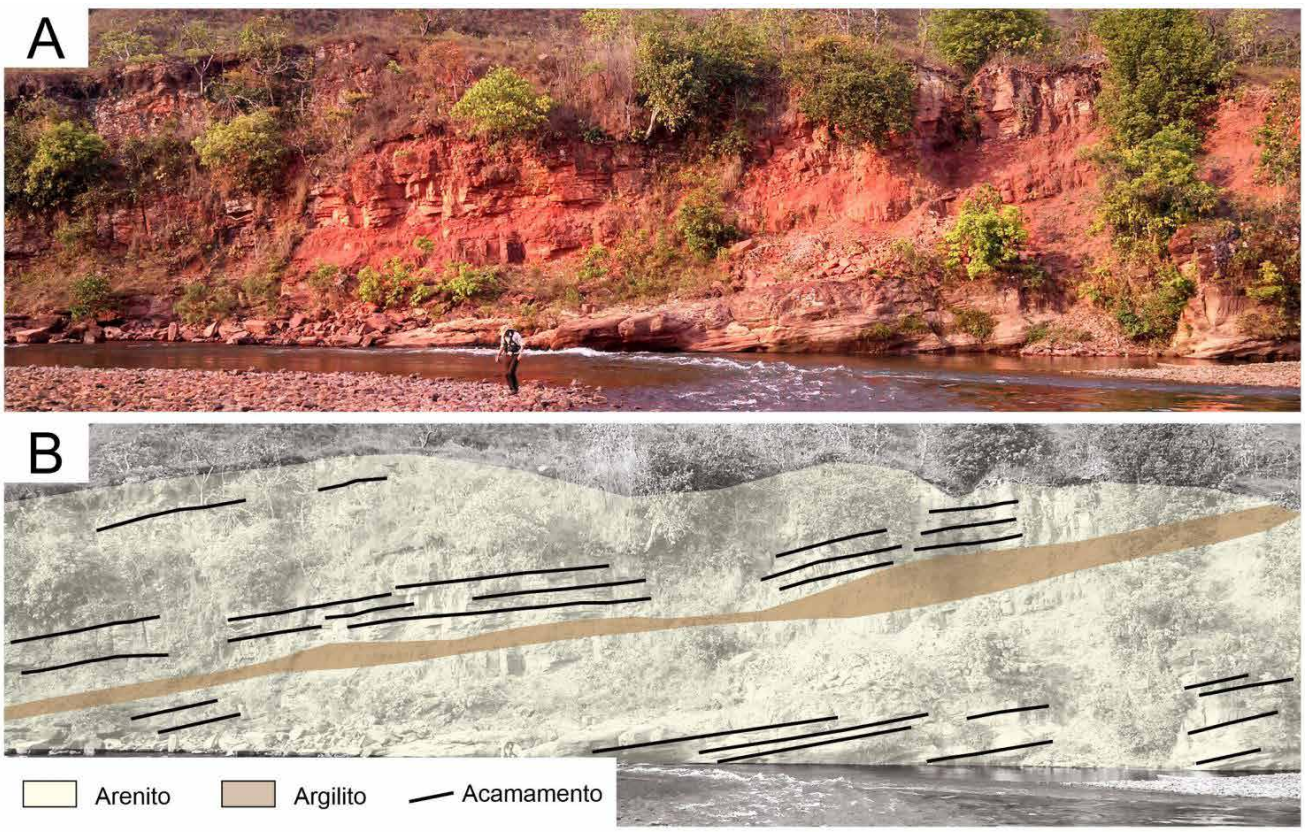

Figura 3 A. Fotografia evidencia a ocorrência de arenitos e argilitos da Formação Aquidauana que ocorrem na bacia do Rio Garças, próximo ao município de Guiratinga, MT; B. Fotografia com a indicação das camadas de rochas sedimentares e estruturas associadas.
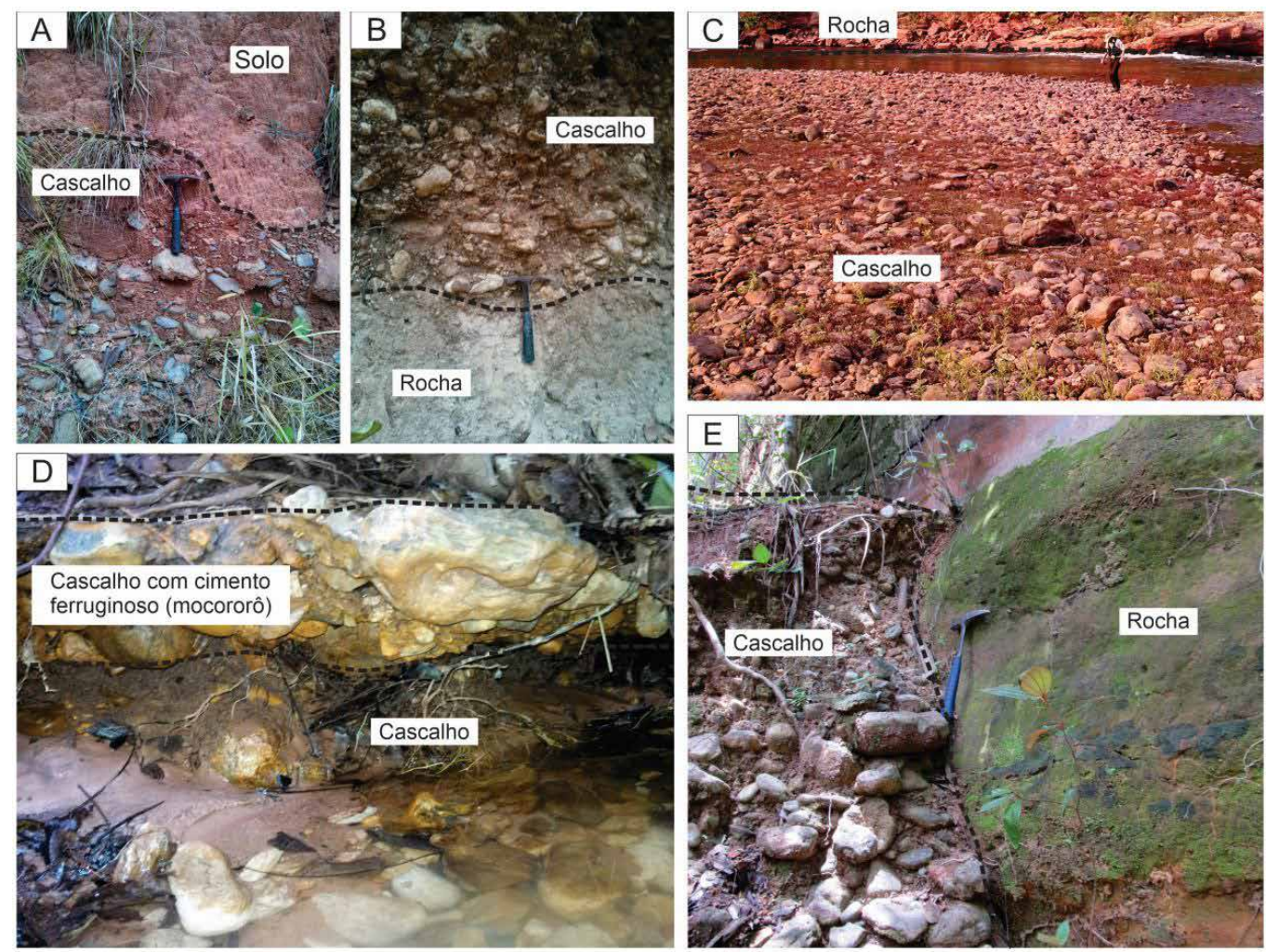

Figura 4 Fotografias evidenciam a ocorrência de cascalhos nas áreas dos garimpos de diamante da região do rio Garças: A. Depósitos de cascalhos coluvionar; B. Terraço; C. Barra de pontal - ajogo, identificados na bacia do Rio Garças. D. Cascalho com cimento ferruginoso (mocororô) recobrindo camadas de cascalhos na região do Garimpo do Xibiu; E. Contato geológico entre um depósito de cascalho fluvial e arenitos da Formação Aquidauana, Garimpo do Xibiu. 


\section{Aquisição de Dados de GPR}

Os trabalhos de campo consistiram na aquisição de seções de GPR, transversais à atual calha do rio Garças, com o foco na identificação dos depósitos de canal, coluviais e de terraços.

As aquisições das seções de GPR ocorreram ao longo de garimpos ativos na margem do rio Garças (Figura 5) onde havia exposições de cascalhos para a calibração da velocidade da onda eletromagnética do meio, bem como correlacionar os refletores com os depósitos sedimentares. No campo usou-se a técnica de aquisição de dados no modo common offset (afastamento constante) que possibilita o delineamento das estruturas geológicas ao longo do percurso percorrido com o equipamento.

Nas aquisições de dados usou-se o sistema GPR SIR3000 acoplado a antenas blindadas de 200MHZ e de
400MHz. Este equipamento foi escolhido em função de sua alta resolução espacial e possibilidade de investigar até a profundidade média de 10 metros, em sedimentos com matriz arenosa (areia e cascalho aluviais).

Durante as duas campanhas de campo, realizaramse testes com os parâmetros de aquisição (intervalos de amostragem temporal e espacial, janela temporal, frequência de amostragem, número de amostras e frequência da antena), com o objetivo de calibrar e obter as melhores respostas para o GPR. Após definidos os melhores parâmetros, usaram-se para a antena de $200 \mathrm{MHz}$ o espaçamento entre os traços de $5 \mathrm{~cm}$, com 1024 amostras por traço, intervalo de amostragem temporal de 0,29 ns e janela temporal de 300 ns. Já os parâmetros de aquisição de campo para a antena de 400 $\mathrm{MHz}$ foram o espaçamento entre os traços de $2 \mathrm{~cm}, 1024$ amostras por traço, intervalo de amostragem temporal de $0,2636 \mathrm{~ns}$ e janela temporal de $270 \mathrm{~ns}$.
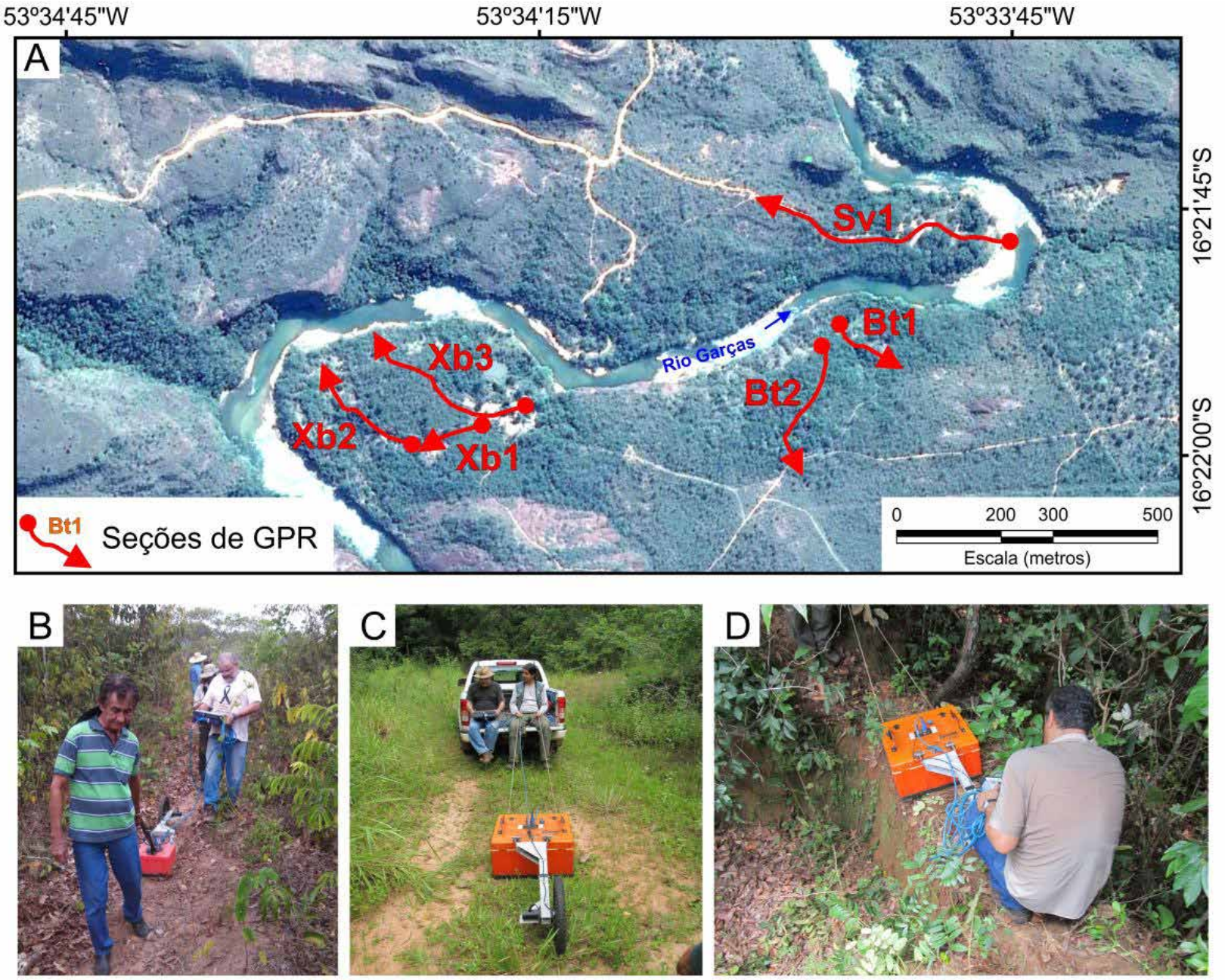

Figura $5 \mathrm{~A}$. Imagem aérea da área de pesquisa com a indicação das seções de GPR realizadas nos garimpos pesquisados. Fotografias evidenciam as aquisições de GPR nas áreas dos garimpos: B. Xibiu, C. Sinvaldo e D. Bertinho. 
No Garimpo do Bertinho a equipe de campo adquiriu duas seções de GPR perpendiculares à atual calha do rio Garças, em função da presença de uma antiga cava de exploração de diamantes na área. Nesta área usou-se apenas a antena de $200 \mathrm{MHz}$ porque não haviam trilhas, assim arrastou-se esta antena na superfície para tombar os arbustos e consequentemente obter-se um bom acoplamento eletromagnético com o subsolo, o que evitou ruídos espúrios gerados pelo soerguimento da mesma. A Linha Bt1 passou ao lado da antiga cava garimpeira, que possui cerca de 105 metros de comprimento e serviu para calibrar a resposta do GPR. A Linha Bt2 foi desenvolvida com o objetivo de interceptar um canal de corte e preenchimento (canoão) identificado em campo.

No Garimpo do Sinvaldo houve a aquisição de uma seção de GPR aproximadamente perpendicular à atual calha do rio Garças, com o objetivo de identificar os sedimentos depositados ao longo da barra de pontal (ajogo). Na aquisição da Linha Sv1 usou-se a antena de 200MHz desde a margem do rio Garças até o local onde afloram arenitos da Formação Aquidauana.

No Garimpo do Xibiu houve um maior detalhamento com o GPR em função da expressiva camada de cascalho evidente na frente de lavra garimpeira. No campo a equipe adquiriu 3 seções de GPR (Xb1, Xb2 e Xb3) com antenas de $400 \mathrm{MHz}$ em função da facilidade no deslocamento do equipamento ao longo das trilhas dos garimpeiros.

\section{Processamento de Dados de GPR}

No processamento dos dados de GPR usou-se o Módulo 2D para a análise de dados no software ReflexW (Sandmeier 2017). No software utilizou-se uma sequência simples de rotinas de processamento em função da boa qualidade dos dados obtidos em campo. Para a obtenção dos resultados de GPR, aplicaram-se as seguintes etapas de processamento:

Ajuste do tempo zero - nesta etapa remove-se o delay inserido nos traços durante a aquisição de dados para evitar a perda do registro do tempo zero que ocorre principalmente quando se usam antenas não blindadas. Assim nesta etapa posiciona-se corretamente o tempo inicial de cada registro na seção de GPR.

Aplicação de ganho de decaimento de energia - este filtro atua de forma independente em cada traço, o que possibilita a multiplicação da amplitude de cada ponto do traço por uma função $g(t)$, tal que:

$$
g(t)=(1+a t) e^{b t}
$$

onde:

$$
\begin{gathered}
a=\frac{a^{\prime}}{\text { largura do pulso }} \\
b=\frac{b^{\prime} V}{8,69}
\end{gathered}
$$

Para b' dado em $\mathrm{dB} / \mathrm{m}$.

A função $g(t)$ evidencia-se em duas partes, uma linear e outra exponencial. A largura do pulso é medida a partir da frequência nominal da antena. As duas variáveis do filtro a' (ganho linear) e b' (ganho exponencial) são modificadas com o objetivo de ressaltar igualmente todas as amplitudes (função linear) e/ou ampliar a amplitude somente nas maiores profundidades (função exponencial). O ganho exponencial se faz útil na amenização de perdas de sinal devido à distância da fonte (Sandmeier 2017).

Utilização de filtro passa banda de frequência - filtro 1D que atua no domínio da frequência com o objetivo de remover ruídos aleatórios registrados nos sinais de GPR. Para os registros de GPR usou-se o filtro $\cos ^{2}$-taper com o auxílio do histograma de frequências de cada seção, a fim de escolher os quatros valores de corte para a frequência nominal do dado em questão. Normalmente, utiliza-se para o primeiro corte (lower-cutoff) um valor correspondente a $1 \frac{1}{4}$ da frequência nominal; para o segundo corte (lower plateau) um valor correspondente a $1 \frac{1}{2}$ da frequência nominal; para o terceiro corte (upper plateau) um valor correspondente a $3 / 2$ da frequência nominal e para o quarto corte (upper cutoff) um valor entre 3 a 6 vezes o valor da frequência nominal (Sandmeier, 2017).

Conversão de tempo para profundidade - nesta etapa necessita-se da velocidade da onda eletromagnética no meio. A velocidade foi obtida através de ajustes hiperbólicos de difrações evidentes em todas as seções de GPR, em função da elevada quantidade de raízes, cascalhos e seixos que causam estas difrações. Além do ajuste hiperbólico, mediu-se a profundidade de uma camada de cascalho em um afloramento, e realizou-se uma seção de GPR sobre o mesmo, com uma antena de $900 \mathrm{MHz}$, o que possibilitou o cálculo da velocidade da onda refletida do GPR $(0,1 \mathrm{~m} /$ ns, Figura 6).

Inserção de topografia - nesta etapa corrigem-se os desníveis topográficos de cada traço da seção de GPR para reposicionar corretamente os refletores e consequentemente as estruturas geológicas. As cotas altimétricas do GPS foram obtidas com o Modelo Geoidal EGM96 e o Datum vertical WGS84.

Como a janela temporal registrada, nas seções de GPR, foi de $240 \mathrm{~ns}$ procuraram-se refletores até a profundidade de 12 metros, todavia, com a absorção do sinal eletromagnético, obteve-se uma profundidade máxima de 9 metros. 


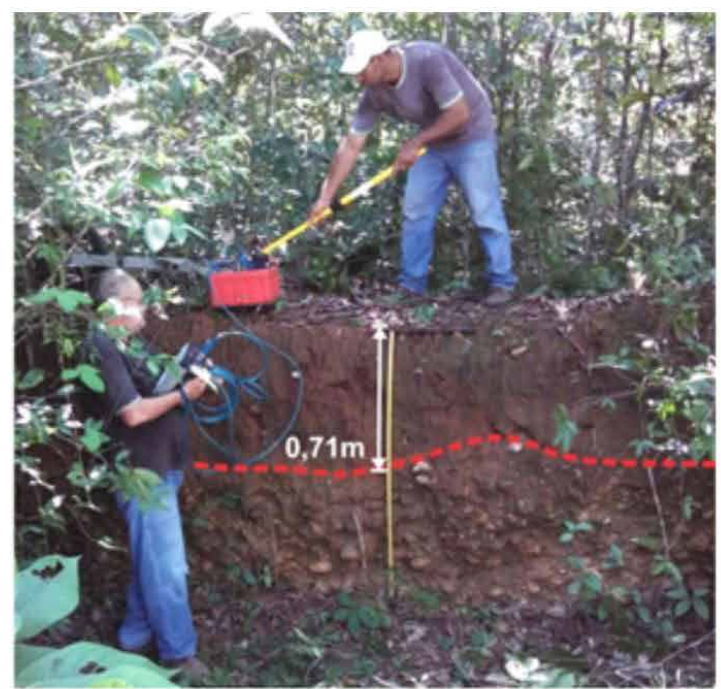

A

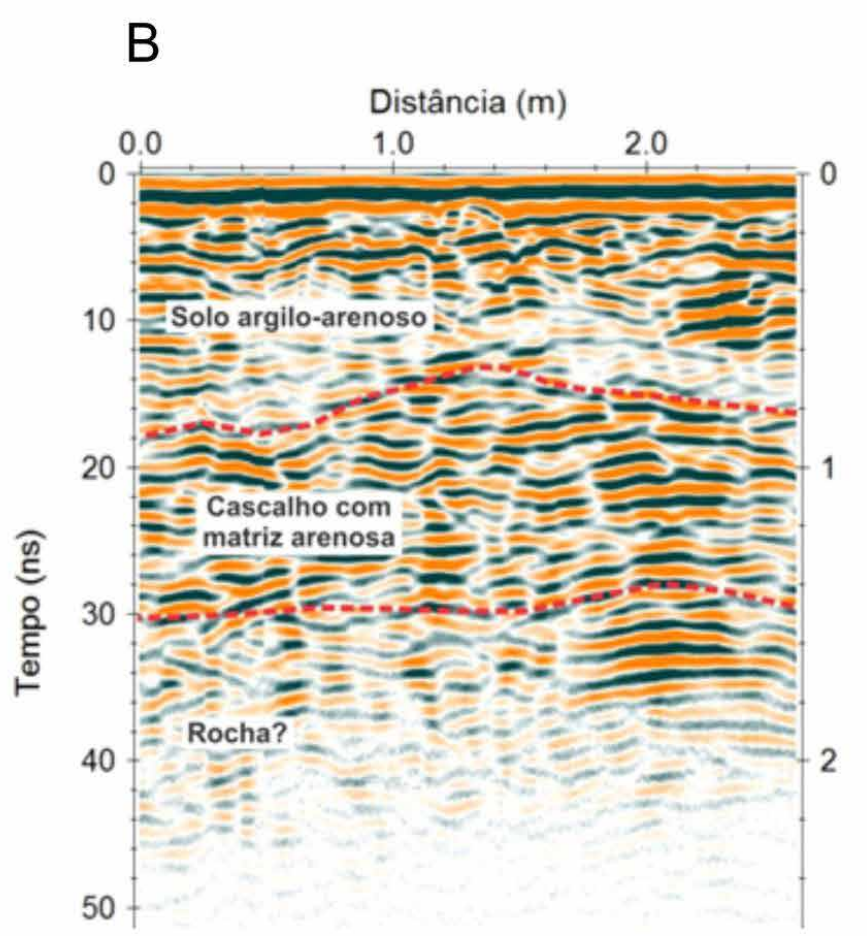

Figura 6. A. Fotografia de um afloramento usado na calibração da velocidade da onda eletromagnética na região dos garimpos de diamante; e B. Respectiva seção de GPR com os limites dos refletores relacionados aos contatos geológicos.

\section{Resultados e Interpretações}

Na interpretação de dados de GPR optou-se pelo uso do termo radarfácies que tem relação direta com as estruturas geológicas e as faixas de frequências registradas pela antena receptora. As interpretações dos dados foram orientadas com a presença de estruturas aflorantes na região de estudo, bem como das características de cada radarfácies. Neal (2004) recomenda que o termo radarfácies seja descrito em termos de forma, mergulho, continuidade e analogia dos refletores.

Na análise dos dados de GPR identificaram-se quatro padrões distintos de reflexão (radarfácies - Rf) nas seções 2D desenvolvidas em todos os garimpos (Tabela 1).

O primeiro padrão de reflexão (Rfs1) é caracterizado pela presença de refletores caóticos de baixa amplitude. Este padrão em muitas seções de GPR, comumente na parte superior das mesmas, com espessuras de 1 a 5 metros. Este padrão é interpretado como um solo argilo-arenoso, homogêneo, sem blocos de rochas e poucas raízes de árvores.

O padrão Rfs2 caracteriza-se pela presença de refletores caóticos de baixa amplitude com a presença de hipérboles de alta amplitude. Este padrão ocorre na parte superior das seções de GPR até a profundidade máxima de 3 metros, e relaciona-se aos solos areno-argilosos com presença de clastos de rochas, raízes de árvores e buracos de pequenos animais.

Os refletores hiperbólicos irregularmente distribuídos, com alta a média amplitude, circundados por refletores de baixa amplitude, individualizam o padrão de reflexão Rfc. O padrão Rfc ocorre de forma restrita nas seções de GPR, sempre abaixo de Rfs 1 ou Rfs2, com espessuras entre 1 a 8 metros. Em função das características relaciona-se Rfc aos depósitos de cascalhos aluvionares e coluvionares que ocorrem na região.

O padrão de reflexão Rfr apresenta refletores inclinados, contínuos, de alta amplitude, circundados por refletores de baixa amplitude. Este padrão ocorre sempre abaixo dos anteriores e distingue as camadas de arenitos da Formação Aquidauana presentes na área.

Após a correlação entre as radarfácies e as respectivas camadas pedológicas e litológicas, realizaram-se as interpretações das seções de GPR 2D realizadas nos garimpos. 
Tabela 1 - Padrões, descrições e interpretações dos refletores identificados com o GPR nos garimpos da região de Guiratinga, MT.

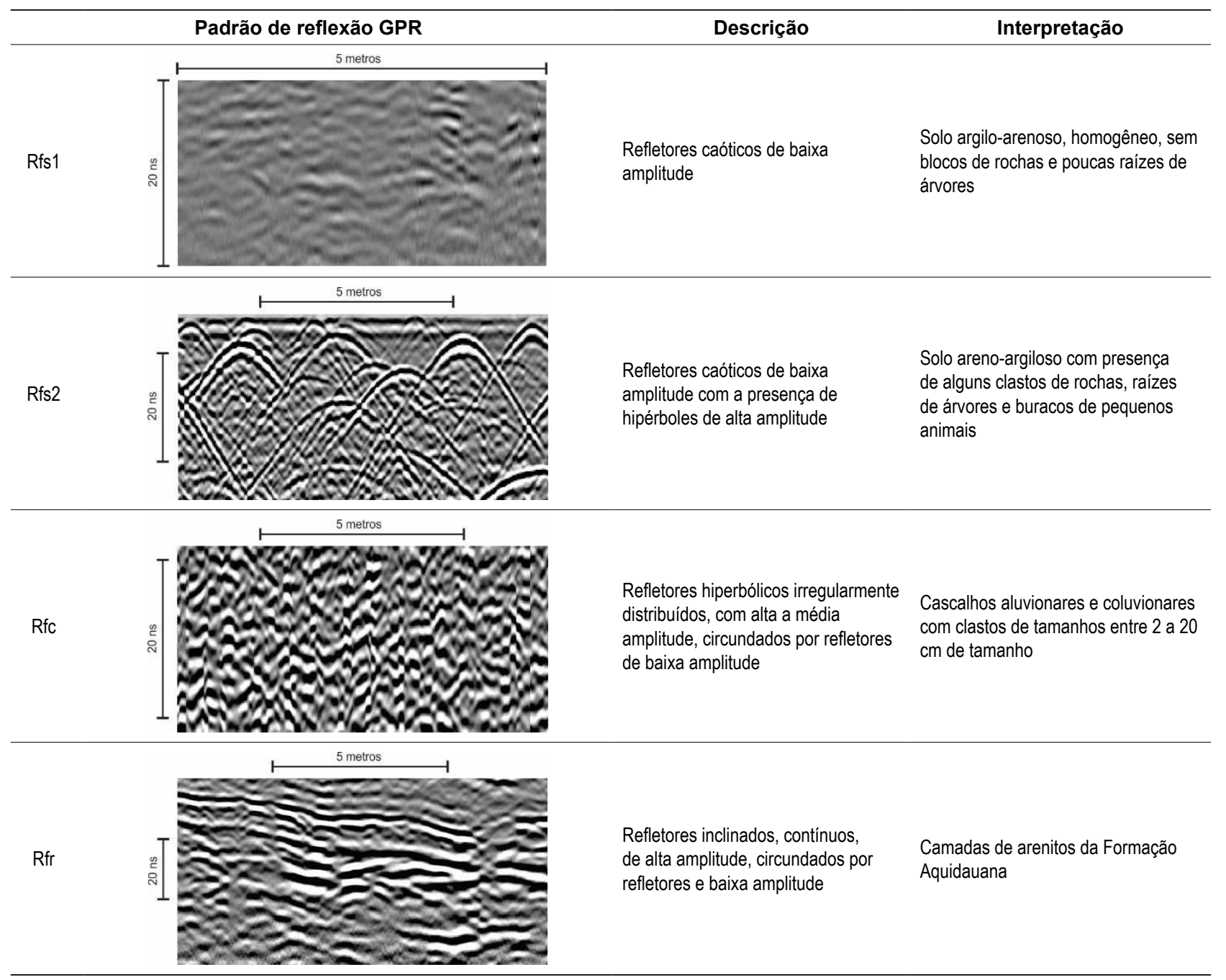

\subsection{Garimpo do Sinvaldo}

Na seção de GPR realizada no Garimpo do Sinvaldo (Figura 7) notam-se três padrões de reflexão relacionados às radarfácies Rfs2, Rfc e Rfr. O padrão Rfs2 ocorre ao longo de toda a seção de GPR Sv1, com espessuras entre 1 e 6 metros, tendo a espessura máxima entre as posições de 180 a 220 metros. A radarfácies Rfc acontece entre 0 e 180 metros, e 230 a 325 metros da seção de GPR. Esta radarfácies possui uma espessura média de 2 metros, com espessura máxima de 4 metros entre as distâncias de 230 a 310 metros. A radarfácies Rfr ocorre abaixo de Rfs 2 e Rfc a partir de 0,5 metro de profundidade no final da seção de GPR (cotas mais elevadas do terreno). O comportamento geométrico do topo da radarfácies $\mathrm{Rfr}$, aliado às descontinuidades de refletores sugerem a presença de inúmeros deslocamentos de blocos rochosos, causados possivelmente por cisalhamentos normais. Entre as posições de 0 a 200 metros, na seção de GPR, notamse abatimentos de blocos similares às estruturas do tipo horsts e grábens, característicos de zonas de falhamentos de extensão (Figura 7).

Na seção Sv1 interpretam-se depósitos coluvionares de cascalho entre as posições de 230 a 310 metros, uma vez que não existem sedimentos fluviais (areias com estratificações) sobrepondo estes depósitos. E depósitos de cascalhos fluviais entre 0 e 180 metros, visto que entre 60 e 100 metros notam-se estratificações cruzadas tabulares dentro da radarfácies relacionada ao solo.

\subsection{Garimpo do Bertinho}

Nas seções realizadas neste garimpo notam-se as radarfácies Rfs2, Rfc e Rfr (Figura 8). Na seção Bt1 a 
radarfácies Rfs2 (solo areno-argiloso) acontece ao longo de todo o perfil com uma espessura média de 3 metros, com um adelgaçamento entre as distâncias de 30 a 65 metros (Figuras 8A e 8B). A radarfácies Rfc (cascalho) ocorre apenas entre as posições de 10 a 32 metros, abaixo da profundidade de 2 metros, com uma espessura aproximada de 5 metros. A radarfácies Rfc (cascalhos) encontrase restrita a uma estrutura do tipo gráben limitada por falhas normais. Na parte basal dessa seção encontra-se a radarfácies Rfr (arenitos da Formação Aquidauana).

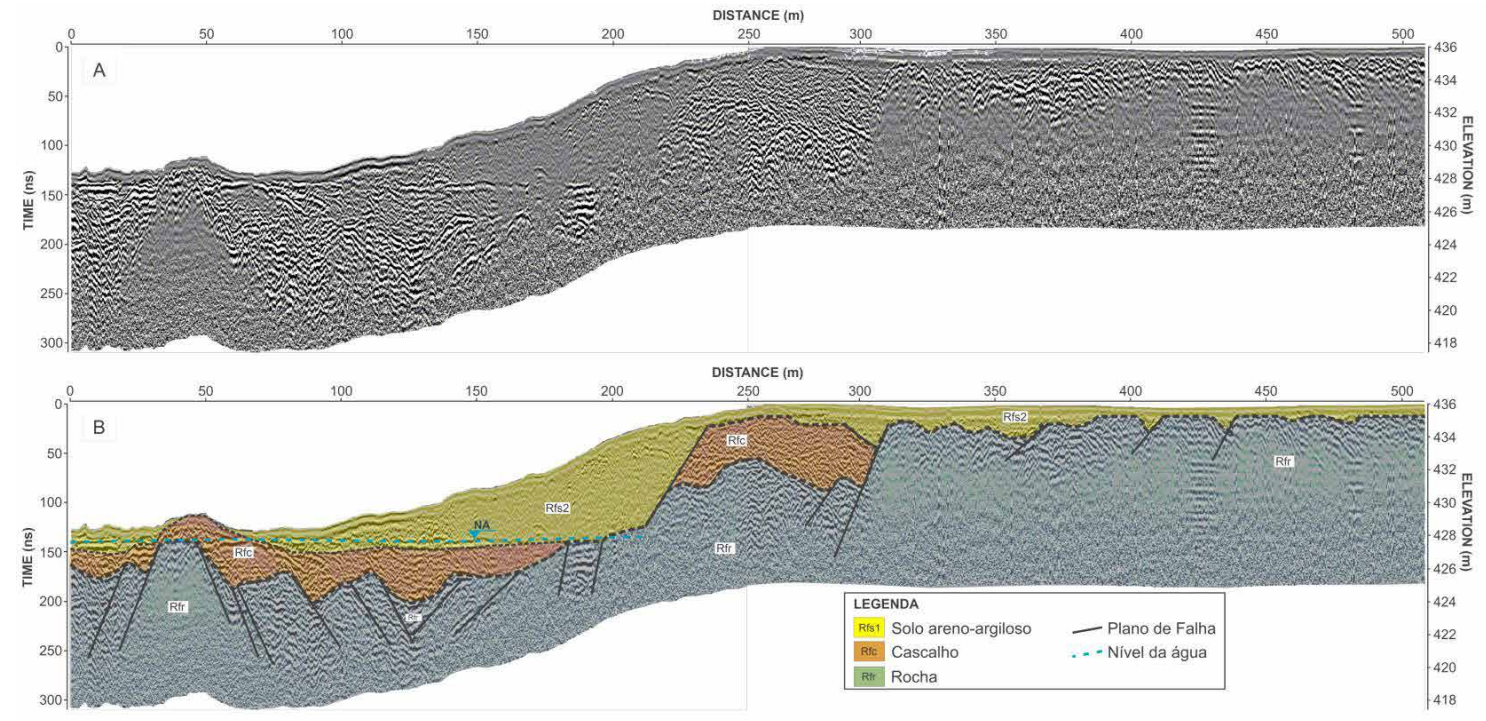

Figura 7 Seção de GPR realizada no Garimpo do Sinvaldo com a delimitação das principais radarfácies e possíveis falhamentos normais. A. Seção sem interpretação. B. Seção interpretada.
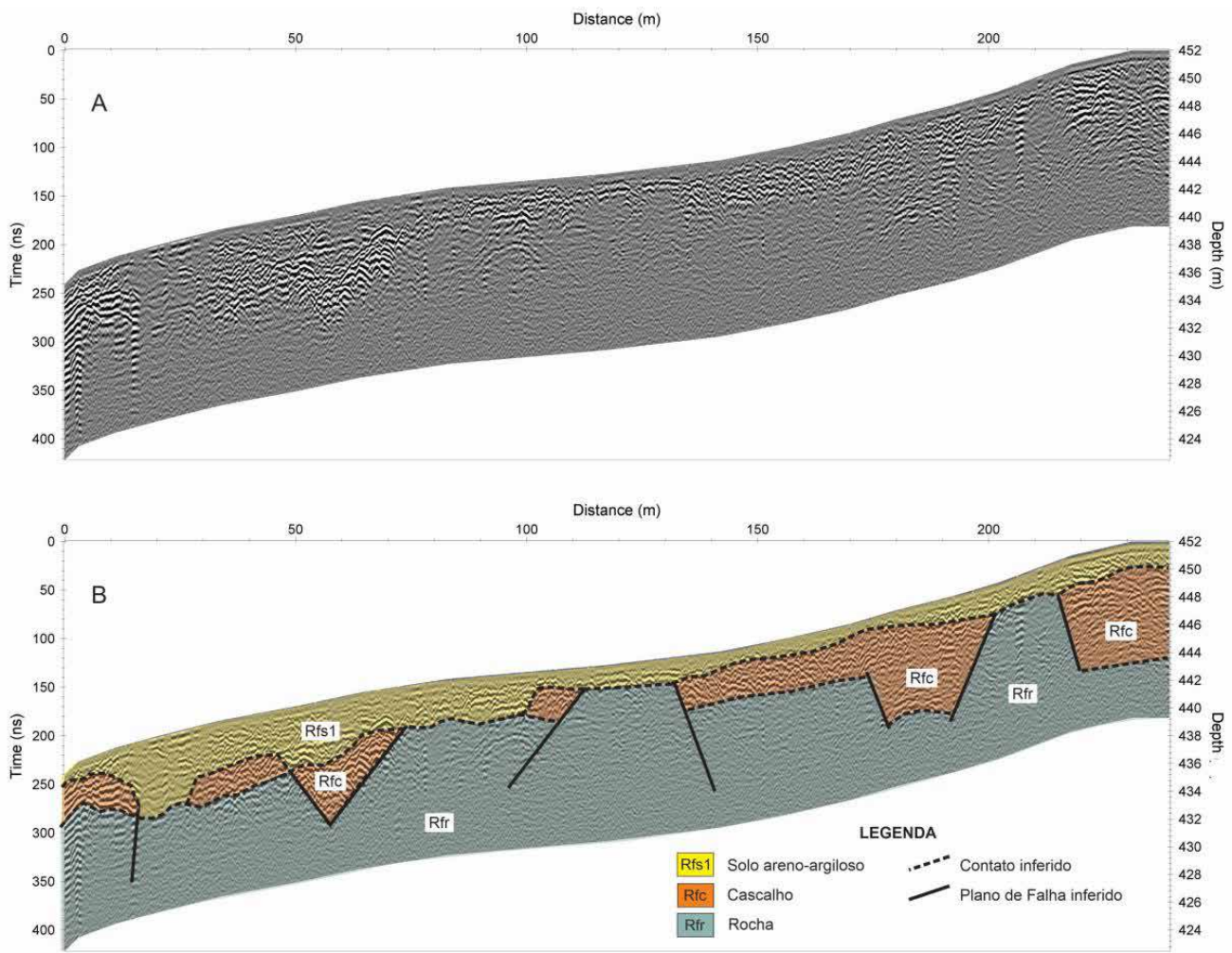

Figura 8 Seção de GPR realizada no Garimpo do Bertinho com a delimitação das principais radarfácies e possíveis falhamentos normais. A. Seção Bt1 sem interpretação. B. Seção Bt1 interpretada. 
Na seção Bt2 do Garimpo do Bertinho (Figura 9) notam-se inúmeras descontinuidades laterais de refletores que sugerem a presença de falhamentos normais, e consequentemente a deposição de cascalhos que caracterizam a radarfácies Rfc (Figuras 9A e 9B). Acima dos cascalhos

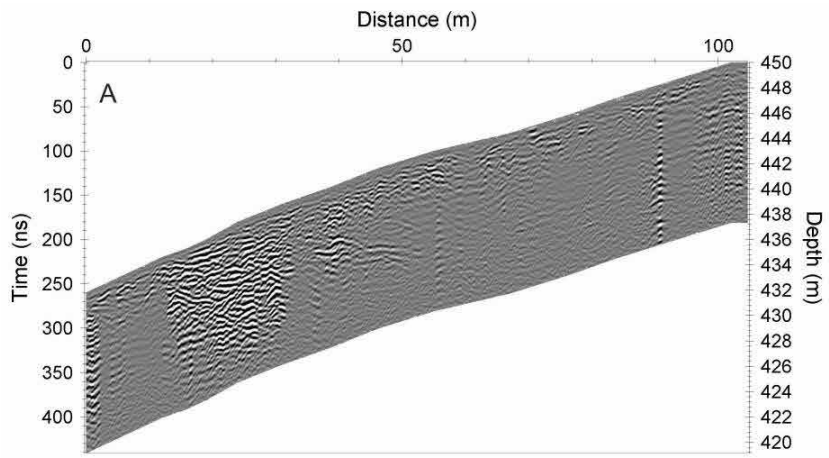

notam-se sedimentos areno-argilosos que distinguem a radarfácies Rfs2 das demais radarfácies. As rochas na área mostram estruturas do tipo horts e grábens, nas rochas sedimentares da Bacia do Paraná, na região sudeste do Mato Grosso.

Figura 9 Seção de GPR realizada no Garimpo do Bertinho com a delimitação das principais radarfácies e possíveis falhamentos normais. A. Seção Bt2 sem interpretação. B. Seção Bt2 interpretada.

\subsection{Garimpo do Xibiu}

A melhor exposição de cascalhos diamantíferos ocorre neste garimpo, visto que a lavra foi paralisada por falta de licenciamento ambiental.

Nas seções de GPR registraram-se todas as radarfácies descritas neste trabalho (Rfs1, Rfs2, Rfc e Rfr; Figuras 10, 11 e 12). Na seção da Linha Xb1 (Figuras 10A e 10B) identifica-se o solo areno-argiloso (Rfs2) cobrindo todas as demais radarfácies. O solo areno-argiloso mostra uma espessura de 1,5 a 3 metros. Na seção Xb1 é o único local onde se identifica um solo argilo-arenoso (Rfs1) em todas as áreas, possivelmente pelo maior conteúdo de argila na matriz do arenito fino identificado na base dos cascalhos. A camada de cascalho (Rfc) acontece de 80 até 125 metros na seção Xb1, com espessuras entre 1 a 1,2 metros. Abaixo das radarfácies ocorre um arenito fino (Rfr) com a presença de uma estrutura relacionada a um falhamento normal na posição de 55 a 85 metros.

Na seção de GPR Xb2 (Figura 11) nota-se um solo areno-argiloso (Rfs2) em todo o perfil com espessuras entre 1,5 a 5 metros. Os depósitos de cascalho (Rfc) ocorrem do início do perfil até a distância de 145 metros, com espessura máxima ( 9 metros) na posição de 50 metros. No embasamento rochoso (Rfr) identificaram-se 3 estruturas nas posições de 50, 110 e 150 metros, características de falhas normais.

Na seção Xb3 (Figura 12) evidencia-se um solo areno-argiloso (Rfs2) depositado sobre o embasamento

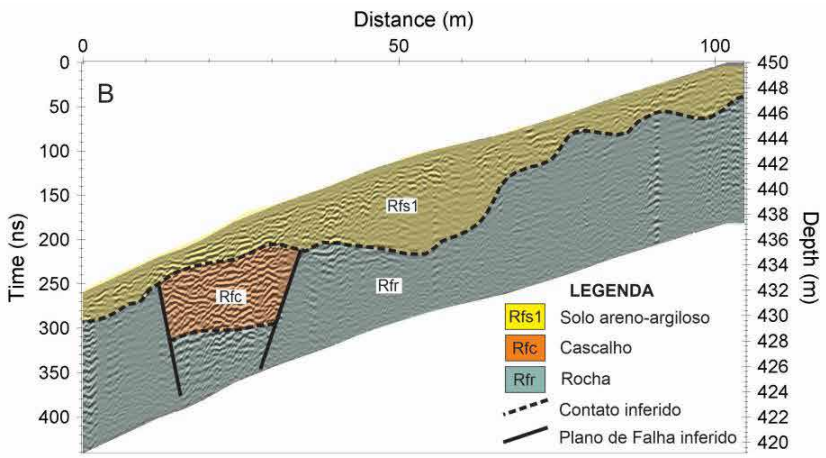

rochoso (Rfr) entre as posições de 0 a 30 metros, e entre 265 a 350 metros, nos demais locais este solo recobre os depósitos de cascalhos diamantíferos (Rfc). Estes cascalhos encontram-se restritos às depressões no embasamento causadas por abatimentos de blocos de rochas provocados por falhamentos normais.

\section{Conclusões}

Os padrões de reflexão identificados com o GPR e correlacionados com informações diretas de exposições de solos, cascalhos e rochas, evidenciam a potencialidade do método como ferramenta de auxílio na prospecção de depósitos de cascalhos diamantíferos nas margens do rio Garças, no estado de Mato Grosso.

Os cascalhos mostram padrões de reflexão distintos dos demais em função das características de refletores hiperbólicos irregularmente distribuídos, com alta a média amplitude, circundados por refletores de baixa amplitude.

A matriz arenosa dos cascalhos e das rochas do bedrock proporcionaram uma boa penetração do sinal do GPR até a profundidade de 12 metros com a antena blindada de $200 \mathrm{MHz}$, e até a profundidade de 9 metros com a antena de $400 \mathrm{MHz}$.

$\mathrm{Na}$ área pesquisada, os padrões de reflexão evidenciado para o bedrock confirmaram uma geometria de abatimento de blocos. Assim, conclui-se que os depósitos de cascalhos estudados possuem uma distribuição espacial controlada por estruturas geológicas associadas a falhamentos distensivos (falhas normais e pequenos grábens). 


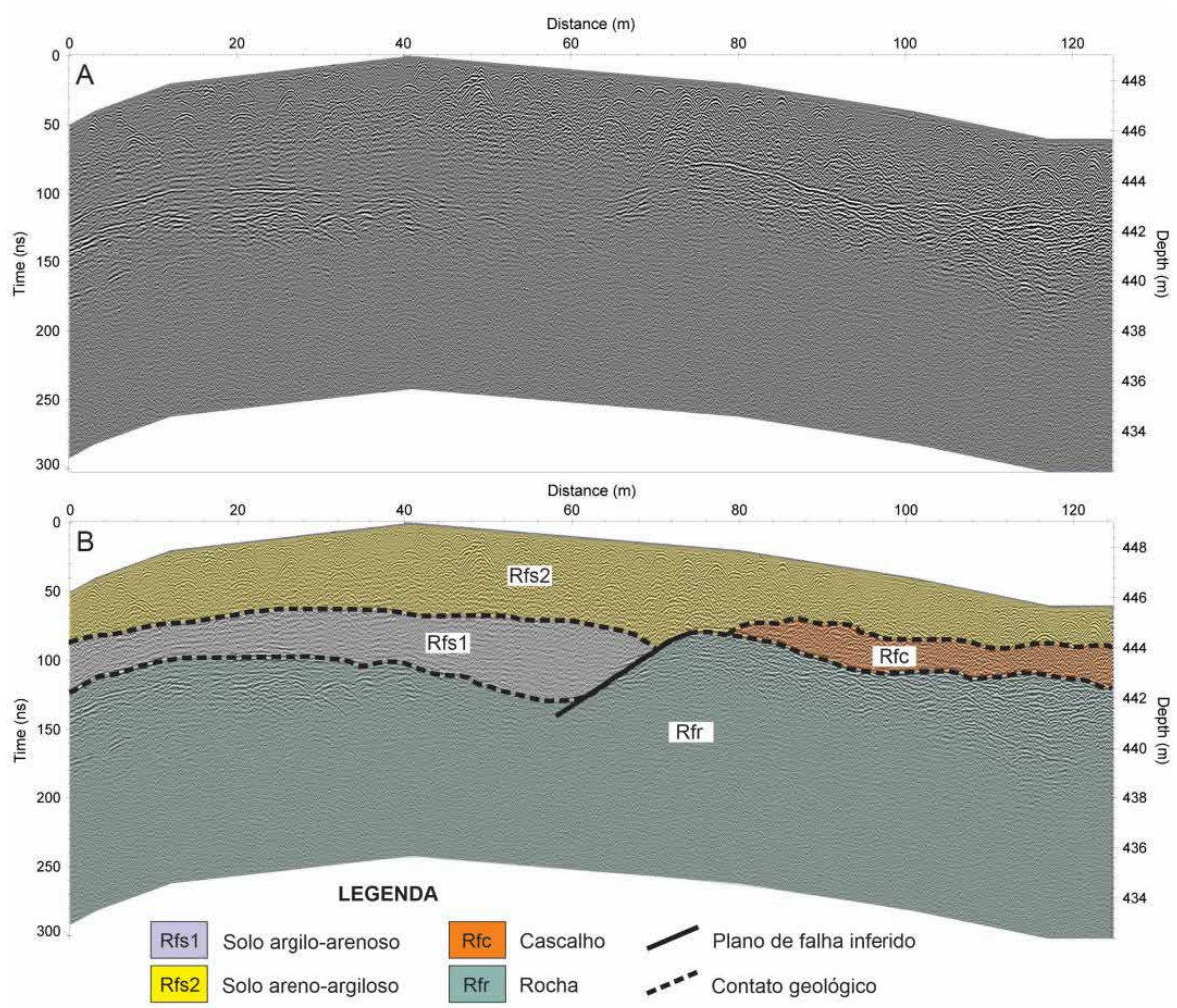

Figura 10 Seção de GPR Xb1 realizada no Garimpo do Xibiu com a delimitação das principais radarfácies e possíveis falhamentos normais. A. Seção Xb1 sem interpretação. B. Seção Xb1 interpretada.

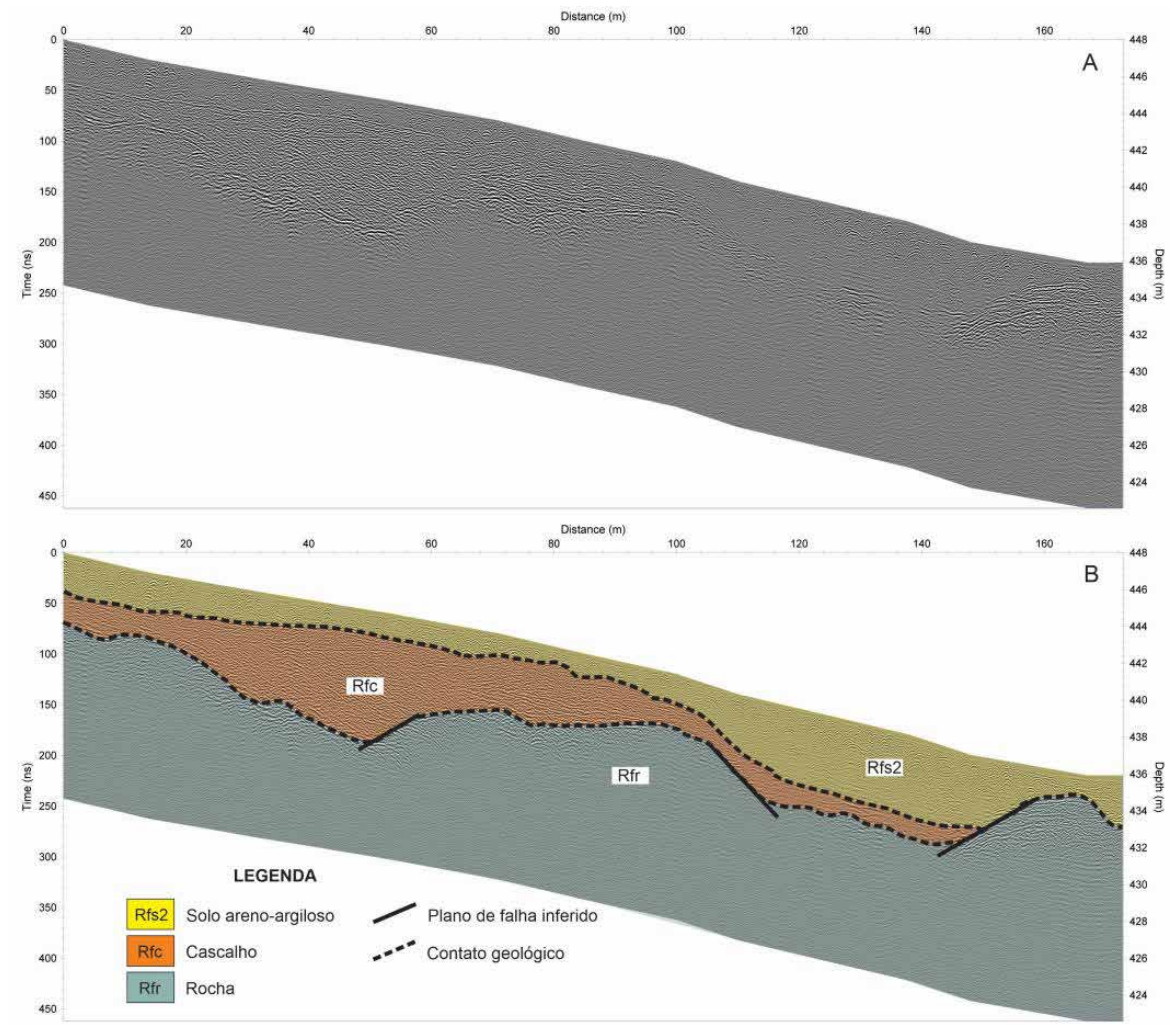

Figura 11 A. Seção de GPR Xb2 sem interpretação. B. Seção Xb2 interpretada. Na seção nota-se a maior espessura de cascalho identificada na área na posição de 50 metros. 


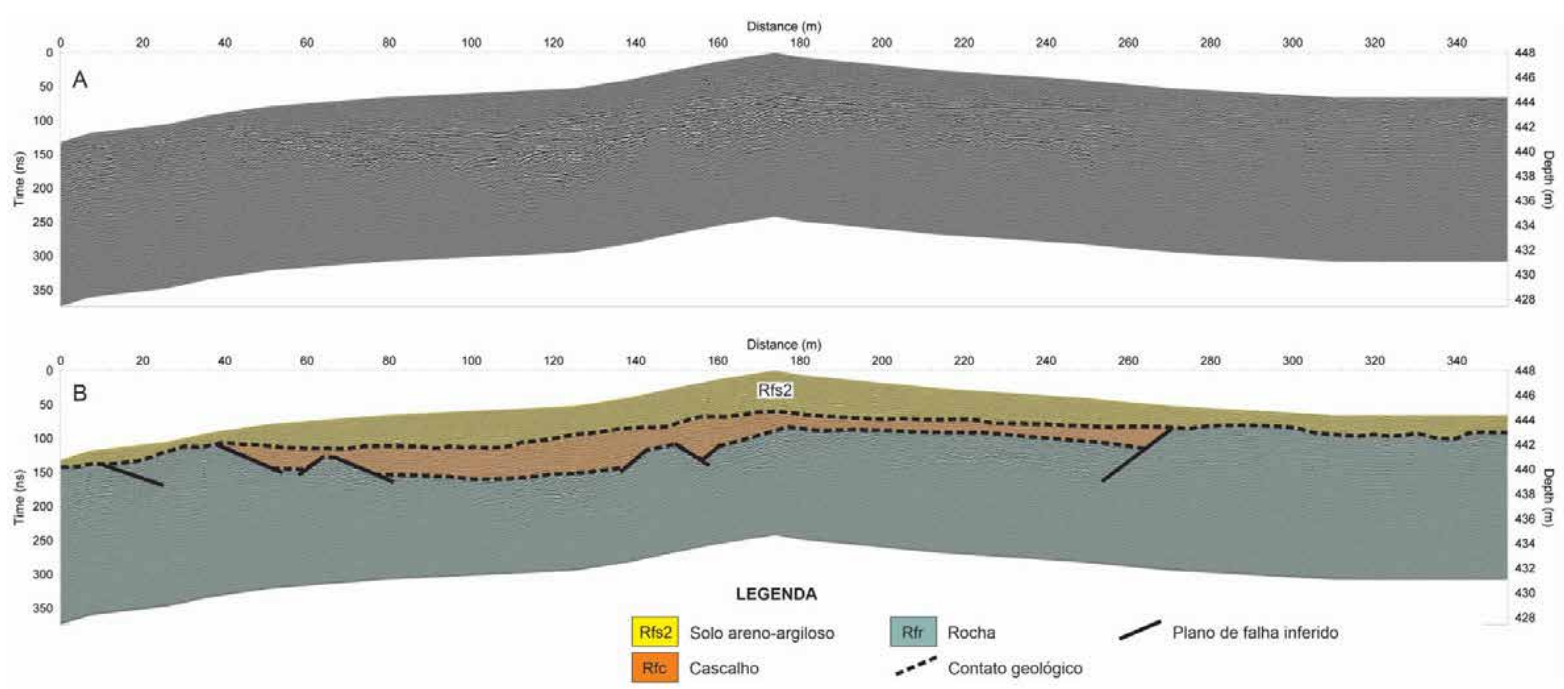

Figura 12 Seção de GPR Xb3 realizada no Garimpo do Xibiu com a delimitação das principais radarfácies e possíveis falhamentos normais. A. Seção Xb3 sem interpretação. B. Seção Xb3 interpretada. Nota-se uma camada de cascalho com 230 metros de comprimento e espessura média de 2 metros.

A relação sedimento/cascalho na área de estudo se mostrou muito baixa, resultado provavelmente da alta capacidade de transporte na bacia do Rio Garças, função da estruturação e modelagem do terreno, que nos terraços aluvionares indicam claramente um processo de contínuo retrabalhamento, bastante similar a outros ambientes geológicos do Cenozoico sobre a Bacia do Paraná no estado de Mato Grosso, como observado por Weska (1996b) nos placeres em Poxoréu.

Em função da ausência de registros da ocorrência de corpos kimberlíticos na região, sugere-se que os cascalhos diamantíferos do rio Garças sejam provenientes do retrabalhamento de conglomerados das formações Utiariti e Salto das Nuvens do Grupo dos Parecis em grande parte erodidos nesta área.

\section{Agradecimentos}

Os autores agradecem à Companhia Matogrossense de Mineração e ao Laboratório de Geofísica Aplicada do Instituto de Geociências da Universidade de Brasília pela disponibilização de recursos para o desenvolvimento do projeto. A equipe amplia seus agradecimentos ao Sr. Helio Goulart, e aos garimpeiros do rio Garças pela inestimável colaboração durante todas as etapas de campo.

\section{Referências}

Assine, M.L., Perinotto, J.A.J., Alvarenga, C.J.S. \& Petri, S. 1998, 'Arquitetura estratigráfica, tratos deposicionais e paleogeografia da Bacia do Paraná (Brasil) no Neo-
Ordoviciano/Eo-Siluriano', Revista Brasileira de Geociências, vol. 28, no. 1, pp. 61-76.

Baxter, M. 1988, Garimpos de Poxoréu: mineradores de pequena escala de diamantes e seu meio ambiente no Brasil, Centro Gráfico do Senado Federal, Brasília.

Bristow, C.S. \& Jol, H.M. 2003, Ground Penetrating Radar in Sediments, Geological Society, London.

Carling, P.A. \& Breakspear, R.M.D. 2006, 'Placer formation in gravel-bedded rivers: A review', Ore Geology Reviews, vol. 28, no 4, pp. 377-401. https://doi:10.1016/j. oregeorev.2005.02.002.

Cavalcanti Neto, M.T.O. \& Rocha, A.M.R. 2010, Noções de Prospecção e Pesquisa Mineral para Técnicos em Geologia e Mineração. Editora do IFRN-RN.

Daniels, J.J. 1996, Surface Penetrating Radar, The Institution of Eletrical Engineers, London, United Kingdom.

Davis, J.L., Annan, A.P. \& Vaughan, C.J. 1984, 'Placer exploration using radar and seismic methods', SEG Technical Program Expanded Abstracts, https://doi:10.1190/1.1894034.

Ekes, C., Hickin, A., Matysek, P. \& Kinnan, E. 2002, ‘Application of ground-penetrating radar in placer mining: a case study from Guyana's Potaro region', Ninth International Conference on Ground Penetrating Radar, https://doi:10.1117/12.462277.

Els, G. \& Eriksson, P. 2006, 'Placer formation and placer minerals', Ore Geology Reviews, vol. 28, no. 4, pp. 373-75, https:// doi:10.1016/j.oregeorev.2005.02.001.

Fedorova, L.L., Sokolov, K.O., Savvin, D.V., Fedorov, V.N. \& Kulyandin, G.A. 2014, 'GPR modeling of placer deposits geological profiles of permafrost zone', Proceedings of the 15th International Conference on Ground Penetrating Radar, https://doi:10.1109/icgpr.2014.6970432.

Francke, J. 2012, 'A review of selected ground penetrating radar applications to mineral resource evaluations', Journal 
of Applied Geophysics, vol. 81, pp. 29-37, https://doi. org/10.1016/j.jappgeo.2011.09.020.

Jol, H.M., Parry, D. \& Smith, D.G. 1998, 'Ground penetrating radar: applications in sand and gravel aggregate exploration' in P.T. Bobrowsky \& A.A. Balkema (eds), Aggregate Resources: A Global Perspective, Rotterdam, Netherlands, pp. 295-306.

Konstantinovskii, A.A. 2003, 'Epochs of Diamond Placer Formation in the Precambrian and Phanerozoic', Lithology and Mineral Resources, vol. 38, pp. 530-46, https://doi. org/10.1023/A:1027316611376.

Kužvart, M. \& Böhmer, M. 1986, 'Prospecting and exploration of placer deposits' in M. Kužvart \& M. Böhmer, Prospecting and Exploration of Mineral Deposits, vol. 21, Developments in Economic Geologic, Elsevier, pp. 409-26.

Lacerda Filho, J.V., Abreu Filho, W., Valente, C.R., Oliveira, C.C. \& Albuquerque, M.C. 2004, 'Mapa Geológico do Estado de Mato Grosso. Escala 1:1.000.000', in Geologia e Recursos Minerais do Estado de Mato Grosso, CPRM, Secretaria de Estado de Indústria, Comércio, Minas e Energia do Estado de Mato Grosso (SICME-MT), Relatório Técnico.

Marshall, T.R. \& Baxter-Brown, R. 1995, 'Basic principles of alluvial diamond exploration', Journal of Geochemical Exploration, vol. 53, no. 1, pp. 277-92, https:// doi:10.1016/0375-6742(94)00067-1.

Milani, E.J., Melo, J.H.G., Souza, P.A., Fernandes, L.A. \& França, A.B. 2007, Bacia do Paraná, Boletim de Geociências da Petrobras, Rio de Janeiro, vol. 15, no. 2, pp. 265-87.
Neal, A. 2004, 'Ground Penetrating Radar and Its Use in Sedimentology: Principle, Problem and Progress', Earth Science Reviews, vol. 66, no 1-3, pp. 261-330, https://doi. org/10.1016/j.earscirev.2004.01.004.

Patyk-Kara, N.G. 2008, 'Sedimentogenesis and placer formation', Lithology and Mineral Resources, vol. 43, no. 4, pp. 318-25, https://doi:10.1134/s0024490208040044.

Porsani, J.L. 1999, ‘Ground Penetrating Radar (GPR): Proposta metodológica de emprego em estudos geológico-geotécnicos nas regiões de Rio Claro e Descalvado - SP', Tese de Doutorado, IGCE/UNESP, Rio Claro, São Paulo.

Sandmeier, K.J. 2017, REFLEXW Version 8.5 for Windows $X P / 7 / 8 / 10$, Program for the processing of seismic, acoustic or electromagnetic reflection, refraction and transmission data, Manual.

Stanaway, K.J. 2012, 'Ten placer deposit models from five sedimentary environments', Applied Earth Science, vol. 121, no 1, pp. 43-51, https://doi:10.1179/174327581 $2 \mathrm{y} .0000000020$.

Weska, R.K. 1996a, 'A prospecção aluvionar de diamantes a partir do entendimento de armadilhas "traps", Anais do $39^{\circ}$ Congresso Brasileiro de Geologia, Salvador, Sociedade Brasileira de Geologia, vol. 3, pp. 189-191.

Weska, R.K. 1996b, 'Geologia da região diamantífera de Poxoréu e áreas adjacentes, Mato Grosso', Tese de Doutorado, IG/ USP, São Paulo.

\section{Como citar:}

Barros, M.V.P., Borges, W.R., Seimetz, E.X. \& Weska, R.K. 2021, 'Potencial Prospectivo do GPR na Identificação de Depósitos Diamantíferos Aluvionares na Região de Guiratinga, Mato Grosso - Brasil', Anuário do Instituto de Geociências, vol. 44: 38488 . https://doi. org/10.11137/1982-3908_2021_44_38488 